\title{
BMJ Open Physical activity and sport participation among adolescents: associations with mental health in different age groups. Results from the Young-HUNT study: a cross-sectional survey
}

Maren Hjelle Guddal, ${ }^{\oplus 1,2}$ Synne Øien Stensland, ${ }^{1,3}$ Milada Cvancarova Småstuen, ${ }^{1,4}$ Marianne Bakke Johnsen, ${ }^{1,2}$ John-Anker Zwart, ${ }^{1,2}$ Kjersti Storheim ${ }^{1,4}$

To cite: Guddal MH,

Stensland $\boldsymbol{\emptyset} \emptyset$, Småstuen $\mathrm{MC}$, et al. Physical activity and sport participation among adolescents: associations with mental health in different age groups. Results from the Young-HUNT study: a crosssectional survey. BMJ Open 2019;9:e028555. doi:10.1136/ bmjopen-2018-028555

- Prepublication history and additional material for this paper are available online. To view these files, please visit the journal online (http://dx.doi org/10.1136/bmjopen-2018028555).

Received 13 December 2018 Revised 22 June 2019 Accepted 26 June 2019
D) Check for updates

(c) Author(s) (or their employer(s)) 2019. Re-use permitted under CC BY-NC. No commercial re-use. See rights and permissions. Published by BMJ.

For numbered affiliations see end of article.

\section{Correspondence to} Ms Maren Hjelle Guddal; m.h.guddal@studmed.uio.no, magudd@ous-hf.no

\section{ABSTRACT}

Objectives Knowledge of how physical activity (PA) and sport participation are related to mental health throughout adolescence is scarce. Our objective was to describe PA levels and sport participation in a population-based sample of adolescents, and to explore how they relate to mental health in different age groups.

Design A population-based cross-sectional study. Setting and participants The adolescent part of the Nord-Trøndelag Health Study, a Norwegian populationbased health survey, conducted from 2006 to 2008. Of 10464 invited participants (age 13-19 years), 7619 (73\%) participated, of whom 3785 (50\%) were boys. Outcome measures Mental health outcomes included psychological distress assessed using a short version of the Hopkins Symptom Check List Five items, selfesteem assessed using a short version of the Rosenberg Self-Esteem Scale and life satisfaction assessed with a single-item satisfaction with life measure.

Method Logistic regression models were used to estimate the likelihood of psychological distress, low self-esteem and low life satisfaction, according to self-reported PA level and type of sport participation, stratified by gender and school level (junior vs senior high school).

Results Fewer senior high school students participated in team sports compared with junior high school students $(p<0.001)$. Physically active adolescents and participants in team sports had higher self-esteem and life satisfaction. A high PA level, compared with a low PA level, was associated with reduced odds of psychological distress among senior high school students (0R $0.63,95 \% \mathrm{Cl} 0.46$ to 0.86 for girls and $\mathrm{OR} 0.46,95 \% \mathrm{Cl} 0.27$ to 0.79 for boys). Team sport participation was associated with reduced odds of psychological distress in senior high school girls.

Conclusion A high PA level was favourably associated with various dimensions of mental health, especially for adolescents in senior high school. Team sport participation may have a positive impact on mental health and should, therefore, be encouraged.

\section{Strengths and limitations of this study}

- Large population-based sample of adolescents with a high participation rate.

- Comprehensive information about sport participation and validated measures of mental health across adolescent age groups.

- Stratified analysis that takes potential age and gender differences during adolescence into account, and adjustments for possible confounders including exposure to interpersonal violence (physical violence, bullying and sexual abuse).

- The main limitation of this study is the cross-sectional study design.

- Measures of physical activity were self-reported.

\section{INTRODUCTION}

Physical activity (PA) and psychological wellbeing are essential to healthy development and quality of life in adolescence. ${ }^{1-3}$ Health behaviours, including the habit of engaging in regular PA, are often established during this period, ${ }^{45}$ paving the way for long-term health prospects.

Maintenance of PA throughout adolescence is of major importance in a public health perspective. Engaging in PA and sports during adolescence is associated with the development of lifelong $\mathrm{PA}^{6-8}$ and psychological well-being. ${ }^{9}$ Yet adolescents tend to be less physically active with increasing age. ${ }^{10}$ The most dramatic decrease in PA is found to occur between the ages of 15 and 16 , around the transition from junior to senior high school. ${ }^{11}$ Although few adolescents are satisfying the recommended $60 \mathrm{~min}$ of moderate to vigorous PA per day worldwide, ${ }^{12} 13$ sport participation is found to be high in some population-based studies. ${ }^{6} 14$ However, the information about participation 
rates in various type of sports throughout adolescence is lacking.

Mental health problems are another major challenge among adolescents; currently, the leading cause of health-related disability within this age group, affecting up to $20 \%$ of adolescents worldwide. ${ }^{1516}$ Prevalence rates of psychological distress, such as anxiety and depression, increase with age, especially from the mid-teens (14-16 years) ${ }^{11}{ }^{17}$ Poor mental health also tends to carry over into adulthood, ${ }^{17} 18$ highlighting the importance of preventive efforts during adolescence. Currently, the evidence indicates that PA may have a positive impact on anxiety, depression and self-esteem among adolescents, although our knowledge is limited. ${ }^{1}$ Studies commonly assess these relationships without considering different developmental stages during adolescence. Further, the need for PA measures that account for various types of sports/activities has been emphasised. ${ }^{1}$ No large population-based studies have evaluated PA levels and type of sport participation in relation to mental health among girls and boys in different adolescent age groups. Identification of these relationships could have implications for preventive programmes and may contribute to more accurate strategies for increasing engagement in PA and improving mental health among adolescents.

The aim of this study was to describe PA levels and the frequency of sport participation in a large population-based sample of adolescents stratified by age group (junior vs senior high school students) and gender. Further, to explore associations between PA level, type of sport participation and mental health, including psychological distress, self-esteem and life satisfaction, among boys and girls across adolescent age groups. As early adolescent stage versus mid-late adolescence is characterised by a major shift in psychosocial development tasks, where peer relationships become more salient, ${ }^{19}{ }^{20}$ the social benefits of sports participation may be of greater importance with increasing age through adolescence. We, therefore, hypothesised that a high level of PA and participation in sports would be associated with lower levels of psychological distress, higher self-esteem and greater life satisfaction, particularly among high school students and participants in team sports.

\section{METHODS}

\section{Study sample}

From 2006 to 2008, all adolescent residents (age 13-19 years) of the Nord-Trøndelag county in Norway $(n=10464)$ were invited to participate in the third wave of the population-based Nord-Trøndelag Health Study (YoungHUNT3). The attendees completed a comprehensive health-related questionnaire during school hours. Of those invited, $7716(74 \%)$ adolescents responded to the questionnaire and attended a clinical examination. The response rate was $82 \%$ among junior high school students and $69 \%$ among senior high school students. Participants not enrolled in school $(n=84)$ and participants $\geq 20$ years of age $(n=13)$ were excluded from the analyses in this study. Thus, the study sample comprised 7619 participants $(73 \%)$ (online supplementary appendix), of whom $4615(61 \%)$ went to junior high school. All participants in senior high school were $\geq 16$ years old.

\section{Exposure variables}

Leisure time PA level was assessed by a validated question on frequency of PA from WHO Health Behavior in Schoolchildren (WHO HBSC) Survey Questionnaire ${ }^{21} 22$ : Outside school hours: 'How often do you usually exercise in your free time so much that you get out of breath or sweat?'. The level of intensity during exercise where you breathe heavily and/or sweat refers to moderate to vigorous activity. Response alternatives were: every day, 4-6 days/week, 2-3 days/week, 1 day/week, less than every week, less than every month and never. Responses were categorised into three levels of PA: 'low PA' ( $\leq 1$ day/ week) (reference group), 'moderate PA' (2-3 days/week) and 'high PA' ( $\geq 4$ days/week).

Type and frequency of sport participation was assessed by the question: 'How often have you participated in the following activities/sports in the last 12 months?'; endurance sports (eg, cross-country skiing, swimming, running), team sports (eg, soccer, volleyball, handball), strength sports (eg, weightlifting, body-building), technical sports (eg, track and field, alpine skiing, snowboard), aesthetic sports (eg, dance, gymnastics), martial arts (eg, judo, karate, boxing), extreme sports (eg, rafting, rock climbing, paragliding), jogging/walking and other. Four alternatives were given for describing the frequency of participation in each of the sport categories: never, less than once a week, once a week, several times a week. A frequency of 'at least once a week' was defined as active participation. Furthermore, adolescents were classified by their participation in sports into team sports (eg, soccer, volleyball, handball) or individual sports (all other sports). The reference group consisted of those with no or infrequent participation in all the sport categories, as well as those who reported a low level of PA. The groups were mutually exclusive. Responses to 'jogging/walking' were not defined as separate sport activities/participation, as they may also be performed in non-sport contexts. The activity 'jogging/walking' was, however, included in all exposure categories; 'jogging/walking' at least once a week was reported among $61 \%$ of those participating in individual sports, among $71 \%$ of those participating in team sports and among 33\% of those with no/infrequent sport participation or low PA level.

\section{Outcome variables: mental health}

Psychological distress was assessed using a validated short version of the Hopkins Symptom Check List Five-item (SCL-5),${ }^{23}{ }^{24}$ including the phrases: 'During the last 14 days: I have been constantly afraid and anxious; I have felt tense or uneasy; I have felt hopeless about the future; I have felt dejected or sad; I have worried too much about various things'. Responses were scored according 
to four response alternatives ranging from 'not at all bothered' (1) to 'extremely bothered' (4). A mean score was calculated, and a cut-off for symptoms of anxiety and depression was set at a mean score above two. ${ }^{23}$ The SCL-5 version has shown high correlation with the 25-item SCL-25 $(\mathrm{r}=0.92)^{24}$ and good internal consistency (Cronbach's alpha 0.87). ${ }^{23}$

Self-esteem/feelings of self-worth was measured using a short version of the Rosenberg Self-Esteem Scale (RSES) (original 10 items) ${ }^{25}$ including four statements: 'I have a positive attitude toward myself', 'I feel rather useless at times', 'I feel that I don't have much to be proud of', and 'I feel that I am a valuable person, at least equal to other people'. Response alternatives were measured on a 4-point scale ranging from 'I strongly agree' (1) to 'I strongly disagree' (4). For the first and last items, the scores were inversed. A mean score was calculated (range 4-16), with higher scores indicating higher levels of self-esteem. A cut-off was set at a mean score of 10 (midpoint of the scale) to separate low and high self-esteem, corresponding to the recommended cut-off at 25 on the original 10-item RSES (range 10-40). ${ }^{26}$ The four-item version of the RSES is found to correlate at 0.95 with the full scale and to explain $0.90 \%$ of the full-scale variance, and has good internal consistency (Cronbach's alpha 0.80). ${ }^{27}$

Life satisfaction was measured with the question: 'Thinking about your life at the moment, would you say that you by and large are satisfied with life, or are you mostly dissatisfied?' Response alternatives were measured on a 7-point scale ranging from 'very satisfied' (1) to 'very dissatisfied' (7), and were coded into a dichotomous outcome variable where adolescents who responded 1-3 were classified as 'high life satisfaction', and those who responded 4-7 were classified as 'low life satisfaction'. A single-item life satisfaction measure is shown to perform almost as well as the multiple-item Satisfaction with Life Scale (SWLS) ${ }^{28} 29$

\section{Potential confounders}

Data on gender and age were obtained from the Norwegian National Population Registry. Socioeconomic status was based on participants' reports of perceived family economy. Pubertal development was assessed by self-reported pubertal status using the validated Pubertal Development Scale (PDS). ${ }^{30}$ Participants were asked to rate their own growth and to assess pubic hair growth. Further, boys were asked to assess changes in voice and facial hair growth, while girls were asked about age at menarche and breast development. Pubertal changes were reported on scales ranging from 1 (has not begun) to 4 (development completed). Menarche was dichotomised into yes (coded 4) and no (coded 1). The items were summed up and an average PDS score was calculated.

Exposure to interpersonal violence was assessed with questions derived from The University of California at Los Angeles Post-traumatic Stress Disorder Reaction Index Reaction Index ${ }^{31}$ : 'Have you ever experienced any of these events?' (no or yes): (1) Been subjected to violence (beaten or injured), (2) Been subjected to unpleasant/disagreeable sexual acts by someone approximately your own age, (3) Been subjected to unpleasant/ disagreeable sexual acts by an adult and (4) Been threatened or physically harassed by fellow students at school over a period of time. Responses were categorised as 'prior violence', 'prior sexual abuse' (by peer or adult) and 'prior bullying'. ${ }^{32}$

\section{Statistical analyses}

Categorical variables were described with counts and percentages, and continuous variables with mean and SD. Possible associations between gender and age distribution were assessed with $\mathrm{X}^{2}$ tests.

The associations between (1) PA level and (2) type of sport participation and the mental health outcomes were evaluated using multiple logistic regression models. The results are expressed as ORs with 95\% CIs. Analyses were stratified by gender and school level (junior and senior high school). To adjust for potential confounding, age, puberty development (PDS), socioeconomic status, prior violence, sexual abuse (by peer or adult) and bullying were all included in the multiple models. All tests were two sided, and the significance level was set to $5 \%$. Analyses were performed using SPSS V.25 (SPSS).

Due to missing data on pubertal development (PDS score) (13\% in girls, $15 \%$ in boys), a model-based imputation for this variable was performed. Linear regression models stratified by gender were fitted with age and body mass index. Residuals for both models followed standard normal distribution and the model fit was very good. The missing values were replaced with the predicted values. The predicted variables and the original variables for both genders were highly correlated, $r=0.75$ and $r=0.85$ for boys and girls, respectively.

\section{Patient and public involvement}

When preparing for the Young-HUNT3 survey, the HUNT research centre appointed reference groups consisting of student representatives (13-19 years), as well as representatives from the county school authorities and county doctors. Content of the questionnaires, clinical examination, implementation of results and protection of privacy have been discussed with these representatives. Results from the current study have been presented and discussed with the Youth Panel for Research at the Research and Communication Unit for Musculoskeletal Health, Oslo University Hospital. The HUNT research centre has an active information policy and publishes annual newsletters for participants as well as regular reports on the HUNT website (https://www.ntnu.no/hunt/om).

\section{RESULTS}

\section{Characteristics of the study sample}

In total, 3785 boys and 3834 girls were included in the analyses. Characteristics of the study sample are summarised in table 1 . The mean age was 15.8 years (SD 1.7). About $10 \%$ reported living in families with an economy below average, and reports of exposure 
Table 1 Characteristics of the study sample $(n=7619)$

\begin{tabular}{|c|c|c|c|c|}
\hline \multirow[b]{2}{*}{ Characteristics } & \multicolumn{2}{|l|}{ Girls (\%) } & \multicolumn{2}{|l|}{ Boys (\%) } \\
\hline & $\begin{array}{l}\text { Junior high } \\
n=2298\end{array}$ & $\begin{array}{l}\text { Senior high } \\
n=1536\end{array}$ & $\begin{array}{l}\text { Junior high } \\
\mathrm{n}=2317\end{array}$ & $\begin{array}{l}\text { Senior high } \\
n=1468\end{array}$ \\
\hline Age, mean (SD) & $14.6(0.89)$ & $17.6(0.86)$ & $14.6(0.89)$ & $17.5(0.84)$ \\
\hline \multicolumn{5}{|c|}{ Socioeconomic status; family economy, n (\%) } \\
\hline Above average & $297(12.9)$ & $264(17.2)$ & $402(17.4)$ & $319(21.7)$ \\
\hline Average & $1644(71.5)$ & $1077(70.1)$ & $1521(65.6)$ & $939(64.0)$ \\
\hline Below average & $204(8.9)$ & $144(9.4)$ & $141(6.1)$ & $136(9.3)$ \\
\hline Missing & $153(6.7)$ & $51(3.3)$ & $253(10.9)$ & $74(5.0)$ \\
\hline Puberty (PDS score), mean (SD) & $2.90(0.68)$ & $3.49(0.51)$ & $2.56(0.61)$ & $3.34(0.47)$ \\
\hline Missing & $10(0.4)$ & $5(0.3)$ & - & $1(0.0)$ \\
\hline \multicolumn{5}{|l|}{ Interpersonal violence, $\mathrm{n}(\%)$} \\
\hline Physical violence & $122(5.3)$ & $138(9.0)$ & $200(8.6)$ & $246(16.8)$ \\
\hline Missing & $96(4.2)$ & $34(2.2)$ & $167(7.2)$ & $65(4.4)$ \\
\hline Sexual abuse & $123(5.4)$ & $169(11.0)$ & $50(2.2)$ & $44(3.0)$ \\
\hline Missing & $103(4.5)$ & $32(2.1)$ & $170(7.3)$ & $58(4.0)$ \\
\hline Bullying & $140(6.1)$ & $129(8.4)$ & $183(7.9)$ & $117(8.0)$ \\
\hline Missing & $107(4.7)$ & $32(2.1)$ & $170(7.3)$ & $58(4.0)$ \\
\hline \multicolumn{5}{|l|}{ Mental health outcomes } \\
\hline \multicolumn{5}{|c|}{ Psychological distress (SCL-5), n (\%) } \\
\hline SCL-5 $\geq 2$ & $350(15.2)$ & $362(23.6)$ & $111(4.8)$ & $110(7.5)$ \\
\hline SCL-5 $<2$ & $1892(82.3)$ & $1138(74.1)$ & $2093(90.3)$ & $1302(88.7)$ \\
\hline Missing & $56(2.4)$ & $36(2.3)$ & $113(4.9)$ & $56(3.8)$ \\
\hline \multicolumn{5}{|l|}{ Self-esteem (RSES)†, n (\%) } \\
\hline RSES $<10$ & $660(28.7)$ & $442(28.8)$ & $304(13.1)$ & $192(13.1)$ \\
\hline RSES $\geq 10$ & $1499(65.2)$ & $1029(67.0)$ & $1847(79.7)$ & $1199(81.7)$ \\
\hline Missing & $139(6.0)$ & $65(4.2)$ & $166(7.2)$ & $77(5.2)$ \\
\hline \multicolumn{5}{|l|}{ Life satisfaction, n (\%) } \\
\hline Low life satisfaction & $722(31.4)$ & $469(30.5)$ & $373(16.1)$ & $223(15.2)$ \\
\hline High life satisfaction & $1525(66.4)$ & $1050(68.4)$ & $1872(80.8)$ & $1212(82.6)$ \\
\hline Missing & $51(2.2)$ & $17(1.1)$ & $72(3.1)$ & $33(2.2)$ \\
\hline
\end{tabular}

${ }^{*}$ Range 1-4.

†Range 4-16.

PDS, Pubertal Development Scale; RSES, Rosenberg Self-Esteem Scale; SCL-5, Symptom Check List Five item.

to interpersonal violence was higher among senior as compared with junior high school students, with physical violence being more common in boys, sexual violence more common in girls, and bullying more evenly distributed between the sexes. Girls reported more mental health problems than boys, with the highest levels of psychological distress found among girls in high school (table 1).

\section{PA level and sport participation}

More boys reported a high level of PA (45.2\%) compared with girls $(35.4 \%)(p<0.001)$. For both genders, junior high school students reported significantly higher levels of PA than senior high school students (table 2). Of the various sports, team sports were most commonly reported by both girls and boys, with about $60 \%$ of the adolescents participating in such sports at least once a week (table 2). For both genders, participation in team and technical sports was less common among senior high school students as compared with junior high school students $(p<0.001)$. In contrast, a significantly higher proportion of both girls and boys in senior high school were engaged in strength sports compared with those in junior high school. Significantly, more girls than boys participated in aesthetic sports, while a higher proportion of boys participated in strength sports and extreme sports, in both age groups (table 2).

PA and mental health

A high level of PA, compared with a low level of PA, was significantly associated with reduced odds of low 
Table 2 Physical activity (PA) level and sport participation rates in relation to gender and school level

\begin{tabular}{|c|c|c|c|c|c|c|}
\hline & \multicolumn{2}{|l|}{ Girls (\%) } & \multirow[b]{2}{*}{$P$ value } & \multicolumn{2}{|l|}{ Boys (\%) } & \multirow[b]{2}{*}{ P value } \\
\hline & Junior high & Senior high & & Junior high & Senior high & \\
\hline \multicolumn{7}{|l|}{ PA level } \\
\hline Moderate PA & 39.9 & 34.3 & & 33.1 & 28.0 & \\
\hline Low PA & 20.2 & 31.6 & $<0.001^{*}$ & 18.5 & 27.2 & $<0.001^{*}$ \\
\hline \multicolumn{7}{|c|}{ Sport participation ( $\geq 1$ day/week) } \\
\hline Team sports & 64.7 & 49.9 & $<0.001$ & 65.8 & 56.7 & $<0.001$ \\
\hline Endurance sports & 46.0 & 45.5 & 0.63 & 51.4 & 49.4 & 0.06 \\
\hline Aesthetic sports & 25.9 & 27.3 & 0.43 & 6.0 & 5.2 & 0.25 \\
\hline Extreme sports & 1.0 & 0.8 & 0.71 & 4.6 & 4.7 & 0.99 \\
\hline
\end{tabular}

Low $\mathrm{PA}=\leq 1$ day/week, moderate $\mathrm{PA}=2-3$ days/week, high $\mathrm{PA}=\geq 4$ days/week.

Bold numbers, statistically significant, $\mathrm{p}<0.05$.

${ }^{*} X^{2}$ test for trend.

self-esteem and low life satisfaction among all students (table 3). In senior high school students, a high level of PA was significantly associated with reduced odds of psychological distress (OR $0.63,95 \%$ CI 0.46 to 0.86 for girls and OR $0.46,95 \%$ CI 0.27 to 0.79 for boys).

\section{Sport participation and mental health}

Participation in team sports, compared with no/infrequent sport participation, was significantly associated with reduced odds of low self-esteem for girls, both in junior high school (OR $0.45,95 \%$ CI 0.32 to 0.64 ) and senior high school (OR $0.57,95 \%$ CI 0.39 to 0.84 ). A similar non-significant trend was observed in boys (table 4). Participation in individual sports was significantly associated with reduced odds of low self-esteem among senior high school boys (OR $0.37,95 \%$ CI 0.18 to 0.76 ).

Participation in team sports was associated with reduced odds of low life satisfaction, among all girls and among junior high school boys (table 4). Among girls in senior high school, team sport participation was also significantly associated with reduced odds of psychological distress (OR $0.70,95 \%$ CI 0.49 to 1.00 ). In boys and junior high school girls, no statistically significant associations between sport participation and psychological distress were revealed in the adjusted models (table 4).

\section{DISCUSSION}

In this population-based sample of adolescents, PA levels and participation rates in sports were lower among girls, and lower among senior high school students compared with junior high school students. Our results showed that higher levels of PA were favourably associated with self-esteem and life satisfaction throughout adolescence, as well as with reduced likelihood of psychological distress in senior high school students. Further, team sport participation was associated with mental health benefits, especially for girls.

\section{Strengths and limitations}

The main strengths of our study include the large sample size of adolescents from an unselected general population, a high participation rate $(73 \%)$ and the information including frequency of participation in sports. To our knowledge, such comprehensive information about sport participation in relation to gender and age differences has not previously been presented. This information enabled us to examine the relationship between sport participation and mental health outcomes, including the aspect of various types of sports, in contrast to most studies on this topic which mainly focus on general PA. We used validated measures of mental health outcomes. Another strength is that we were able to adjust for a variety of possible confounders, as well as including exposures to interpersonal violence as these exposures may have an impact on both PA behaviours and mental health. ${ }^{33-35}$

The main limitation of this study is the cross-sectional study design, and the resultant inability to demonstrate the direction of the association. Further, as measures were self-reported, the included variables are susceptible to information bias. We have used a single item measure to assess PA, and the variable used to describe sport participation exposure provides a crude measure of frequency of participation. However, WHO HBSC question of PA used in this study has been found to hold acceptable reliability and validity in adolescent samples. ${ }^{2122}$ It should be noted that a proportion of the 'high PA' group in this 
Table 3 Associations between levels of physical activity (PA) and mental health problems (psychological distress, low selfesteem and low life satisfaction) among girls and boys in junior and senior high school

\begin{tabular}{|c|c|c|c|c|}
\hline \multirow[b]{3}{*}{ PA level } & \multicolumn{4}{|l|}{ Outcome } \\
\hline & \multicolumn{2}{|l|}{ Junior high school } & \multicolumn{2}{|l|}{ Senior high school } \\
\hline & Unadjusted & Adjustedł & Unadjusted & Adjusted $\ddagger$ \\
\hline & \multicolumn{4}{|c|}{ OR $(95 \% \mathrm{Cl})$ for psychological distress* } \\
\hline \multicolumn{5}{|l|}{ Girls } \\
\hline Low PA & 1.0 (Reference) & 1.0 (Reference) & 1.0 (Reference) & 1.0 (Reference) \\
\hline Moderate PA & $0.80(0.59$ to 1.07$)$ & 0.86 (0.62 to 1.21$)$ & 0.68 (0.51 to 0.90$)$ & $0.73(0.54$ to 0.99$)$ \\
\hline High PA & 0.67 (0.49 to 0.91$)$ & 0.88 (0.63 to 1.24$)$ & 0.53 (0.39 to 0.72$)$ & $0.63(0.46$ to 0.86$)$ \\
\hline \multicolumn{5}{|l|}{ Boys } \\
\hline Low PA & 1.0 (Reference) & 1.0 (Reference) & 1.0 (Reference) & 1.0 (Reference) \\
\hline Moderate PA & 0.54 (0.32 to 0.90$)$ & 0.56 (0.31 to 0.99$)$ & 0.78 (0.49 to 1.23$)$ & 0.89 (0.53 to 1.49$)$ \\
\hline High PA & 0.58 (0.56 to 0.91$)$ & 0.70 (0.41 to 1.18 ) & $0.38(0.23$ to 0.62$)$ & $0.46(0.27$ to 0.79$)$ \\
\hline
\end{tabular}

OR $(95 \% \mathrm{Cl})$ for low self-esteem $\dagger$

\begin{tabular}{|c|c|c|c|c|}
\hline \multicolumn{5}{|l|}{ Girls } \\
\hline Low PA & 1.0 (Reference) & 1.0 (Reference) & 1.0 (Reference) & 1.0 (Reference) \\
\hline Moderate PA & 0.63 (0.48 to 0.82$)$ & 0.65 (0.49 to 0.87$)$ & 0.68 (0.30 to 0.93$)$ & 0.72 (0.52 to 0.99$)$ \\
\hline High PA & 0.53 (0.40 to 0.70$)$ & $0.59(0.44$ to 0.80$)$ & 0.43 (0.31 to 0.61$)$ & 0.49 (0.34 to 0.70$)$ \\
\hline \multicolumn{5}{|l|}{ Boys } \\
\hline Low PA & 1.0 (Reference) & 1.0 (Reference) & 1.0 (Reference) & 1.0 (Reference) \\
\hline Moderate PA & $0.37(0.24$ to 0.58$)$ & $0.32(0.20$ to 0.53$)$ & 0.66 (0.38 to 1.15$)$ & 0.67 (0.37 to 1.20$)$ \\
\hline High PA & 0.31 (0.20 to 0.48$)$ & 0.33 (0.21 to 0.52$)$ & 0.41 (0.24 to 0.71$)$ & 0.44 (0.25 to 0.79$)$ \\
\hline & \multicolumn{4}{|c|}{ OR $(95 \% \mathrm{Cl})$ for low life satisfaction } \\
\hline \multicolumn{5}{|l|}{ Girls } \\
\hline Low PA & 1.0 (Reference) & 1.0 (Reference) & 1.0 (Reference) & 1.0 (Reference) \\
\hline Moderate PA & 0.60 (0.48 to 0.76$)$ & $0.59(0.45$ to 0.76$)$ & $0.66(0.51$ to 0.85$)$ & 0.68 (0.52 to 0.89$)$ \\
\hline High PA & $0.43(0.34$ to 0.55$)$ & $0.49(0.37$ to 0.63$)$ & 0.45 (0.34 to 0.59$)$ & 0.51 (0.38 to 0.69$)$ \\
\hline \multicolumn{5}{|l|}{ Boys } \\
\hline Low PA & 1.0 (Reference) & 1.0 (Reference) & 1.0 (Reference) & 1.0 (Reference) \\
\hline Moderate PA & 0.67 (0.51 to 0.90$)$ & $0.65(0.47$ to 0.90$)$ & $0.76(0.53$ to 1.08$)$ & 0.73 (0.50 to 1.08$)$ \\
\hline High PA & 0.42 (0.32 to 0.56$)$ & $0.44(0.32$ to 0.60$)$ & 0.44 (0.31 to 0.62$)$ & $0.43(0.30$ to 0.63$)$ \\
\hline
\end{tabular}

Bold numbers: statistically significant associations, $\mathrm{p}<0.05$.

Low $\mathrm{PA}=\leq 1$ day/week, moderate $\mathrm{PA}=2-3$ days/week, high $\mathrm{PA}=\geq 4$ days/week.

${ }^{*} \mathrm{SCL}-5 \geq 2$ (range $0-4$ ).

†RSES $<10$ (range 4-16).

$\ddagger$ Adjusted for age, puberty score (PDS), socioeconomic status, prior physical violence, prior bullying, prior sexual abuse.

PDS, Pubertal Development Scale; RSES, Rosenberg Self-Esteem Scale; SCL-5, Symptom Check List Five items.

study may not fulfil the recommended levels of daily PA according to WHO guidelines ${ }^{36}$ as this group includes all those who played sports or exercised at least 4 days/week. Although measures of psychological distress (SCL-5) and self-esteem (RSES) were shortened versions of the original instruments, the measurement precision of these versions is found to be high and sufficient for use in population-based studies. ${ }^{23} 2427$ Furthermore, dichotomisation of the mental health outcomes makes them prone to misclassification. However, the cut-off values to distinguish those with high versus low degree of psychological distress (SCL-5) and low self-esteem (RSES) have both been shown to be clinically relevant cut-points. ${ }^{23}{ }^{26}$ In contrast to psychological distress, low self-esteem and low life satisfaction were not more prevalent in the older age group, reflecting the measurement of different phenomena. Psychological distress is found to function as a proxy measure of symptoms of anxiety and depression, ${ }^{23} 24$ while self-esteem and life satisfaction are more closely related to subjective well-being, ${ }^{28}{ }^{37}$ which may be more stable traits. 
Table 4 Associations between sport participation and mental health problems (psychological distress, low self-esteem and low life satisfaction) among girls and boys in junior and senior high school

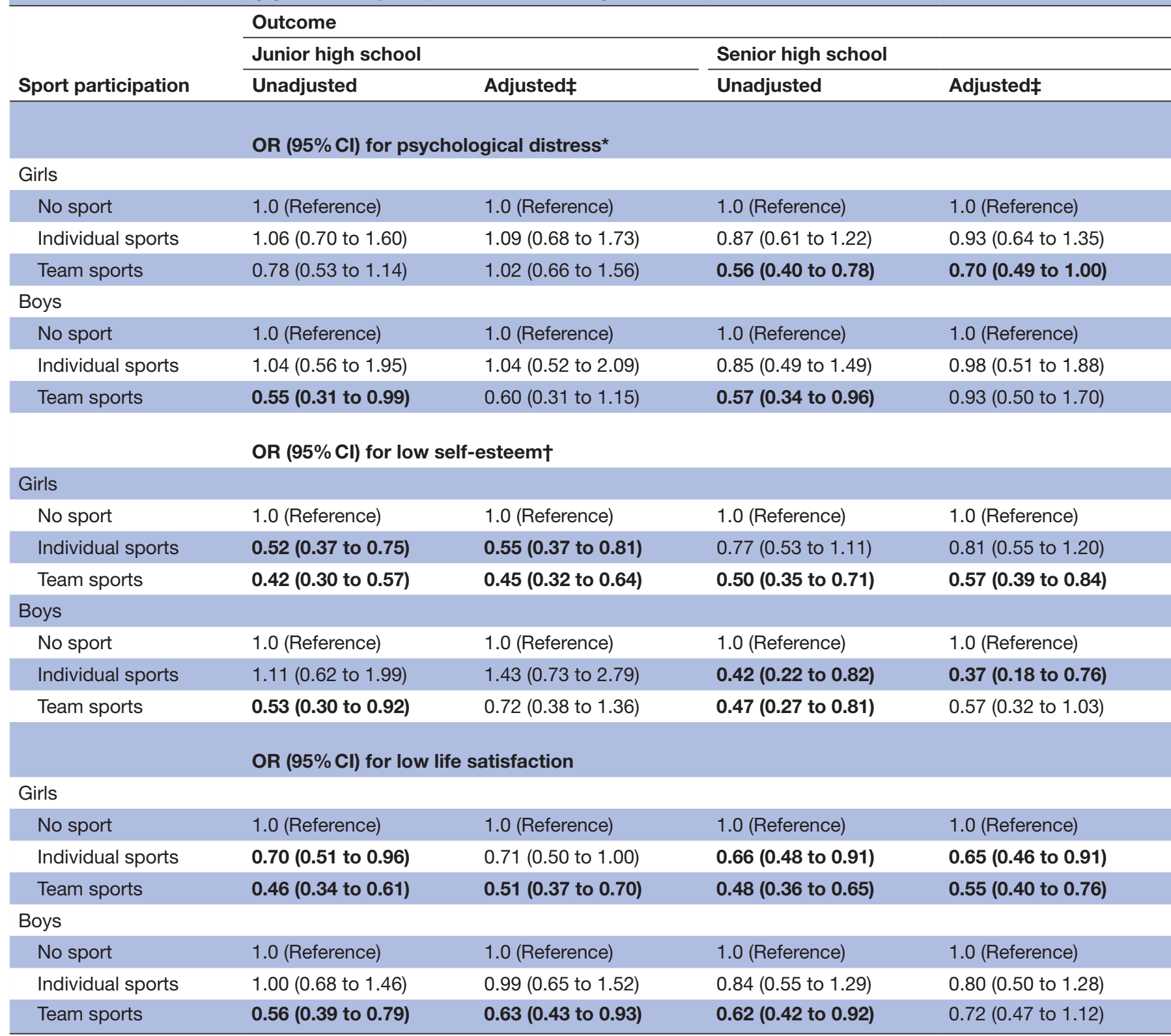

Bold numbers: statistically significant associations, $\mathrm{p}<0.05$.

*SCL5 $\geq 2$ (range 0-4).

†RSES $<10$ (range 4-16).

$\ddagger$ Adjusted for age, puberty score (PDS), socioeconomic status, prior physical violence, prior bullying, prior sexual abuse.

PDS, Pubertal Development Scale; RSES, Rosenberg Self-Esteem Scale; SCL-5, Symptom Check List Five items.

Although the response rate in Young-HUNT3 was high, the lower response among senior high school students compared with junior high school students may represent a selection bias. In Norway, most adolescents start senior high school the year they turn 16. Differences in school systems in other countries, as well as differences related to opportunities for engagement in sports and the organisation of various youth sports may limit the generalisability of the results from this study. Norwegian society is rooted in egalitarian ideals, with 'Sport for All' as a high priority and policy aim $^{38}$; this may be part of the reason why sport participation found in this study is high by international standards. Lastly, the results of this study should be interpreted with caution due to multiple testing, and replication of results is warranted.

Our results according to previous findings and interpretation of findings

The findings from this study confirmed the gender differences in PA levels found in other population-based studies, with girls being less physically active than boys. ${ }^{11-13}$ Also in line with reports from other studies, fewer girls were 
involved in sports. ${ }^{7131439}$ The lower levels of PA and sport participation found among senior high school students confirm findings from previous studies reporting a decline in PA during adolescence, ${ }^{10} 114041$ especially between the ages of 15 and 16 years. ${ }^{11}$ Drop-out from sports for adolescents at this age may be related, in part, to the difficulty of meeting the increasing demands of participation in both school and sport. ${ }^{72}$ However, a systematic review of factors associated with drop-out from organised sports reported that lack of enjoyment and perceptions of competence are the two most dominant factors related to drop-out from sports among adolescents. ${ }^{42}$

The current findings are in line with previous studies reporting associations between adolescents' PA and mental health, including lower likelihood of depressive symptoms, ${ }^{1} 11134344$ as well as greater well-being ${ }^{13}$ and higher self-esteem among those who are physically active. ${ }^{144}$ Longitudinal studies also indicate that PA may protect against the development of depression. ${ }^{45} 46$ Furthermore, PA may be a helpful intervention for adolescents struggling with depressive symptoms. ${ }^{478}$ Regarding engagement in sports, the results of the present study are in accordance with the literature indicating a positive relationship between sport participation and mental health. ${ }^{913} 49-51$

The findings from this study make several contributions to the body of research on the impact of PA and sports on mental health among adolescents. First, age differences were revealed in these relationships, as a high PA level was associated with reduced psychological distress in high school students only. Explanations for why PA and sport participation may be of greater importance in reducing psychological distress among older adolescents could relate to how peer support and interaction play an increasingly important role during adolescence. ${ }^{19} 20$ Thus, social and PAs with peers may be particularly beneficial for older adolescents, helping to distract them from depressive thoughts and to reduce the sense of isolation.

Second, this study shows that the potential beneficial effects related to mental health vary across various types of sport. Participation in team sports, compared with no participation, was more strongly related to beneficial mental health outcomes than individual sports compared with no participation, especially in high school girls. Other studies have reported that organised sports had a greater impact on depressive symptoms among girls than boys, ${ }^{11}$ and that team sports may confer mental health benefits for girls in particular. ${ }^{13}$ A systematic review of the psychological and social benefits of sport participation argued that team sports seem to be associated with more beneficial outcomes compared with individual sports due to the social aspect of being part of a team. ${ }^{9}$ In a recent study of a large representative sample of European adolescents, lower levels of anxiety and depression and higher levels of well-being were found among team sport participants. ${ }^{13}$ Team sport participation during adolescence has also been shown to be associated with lower levels of depressive symptoms in early adulthood. ${ }^{50}{ }^{52}$ In line with this, our findings highlight that the type of sport, including the social aspect of participation, should be considered when examining the impact of sports on mental health among adolescents.

Overall, adolescents with a high PA and team sport participation had lower odds of having low self-esteem than of having psychological distress. These results are in accordance with findings from a review study showing that, of the several mental health outcomes associated with PA in young people, the strongest association was with self-esteem. ${ }^{1}$ It may be that experiences of low self-esteem occur earlier than symptoms of anxiety and depression and that low self-esteem may trigger poor coping behaviour and risk behaviour that subsequently increases the likelihood of mental disorders. ${ }^{53}$ A Cochrane review reports that exercise interventions have positive short-term effects on self-esteem that may help prevent the development of psychological and behavioural problems. ${ }^{54}$

This study contributes to our understanding of the implications lower levels of PA may have on mental health in different phases of adolescence. Regardless of the direction of the association between PA and mental health, inactive adolescents may carry a 'double health burden', with both physical and mental health challenges. To help more adolescents increase or maintain their levels of PA, interventions could include facilitation of a wider variety of sports activities, and at different skill levels, to reach and engage more adolescents. As lack of enjoyment has previously been found to be the most dominant factor related to drop-out from sports ${ }^{42}$, increased focus on the joy of sports may be important in order to reduce drop-out rates during adolescence. In efforts to reduce mental health problems, our results suggest that girls in particular should be a target group for promotion of team sport participation.

\section{CONCLUSION AND IMPLICATIONS}

This study identified gender and age differences in PA and sport participation across adolescent age groups, with the lowest engagement in PA and sports found among girls in senior high school. Our results indicate that a high PA level and sport participation have a positive impact on various dimensions of mental health throughout adolescence, highlighting the importance of continuing with sports in the late teens. The findings underline a need for interventions aimed at maintaining or increasing PA and sport participation, especially for girls around the transition to senior high school. Initiatives to help adolescents continue in team sports may be particularly advantageous. Future studies should examine the effect of interventions for encouraging and increasing PA and sport participation among adolescents, as well as their potential mental health benefits.

\section{Author affiliations}

${ }^{1}$ Research and Communication Unit for Musculoskeletal Health (FORMI), Oslo, Norway 
${ }^{2}$ Faculty of Medicine, Institute of Clinical Medicine, University of Oslo, Oslo, Norway ${ }^{3}$ Norwegian Centre for Violence and Traumatic Stress Studies, NKVTS, Oslo, Norway ${ }^{4}$ Faculty of Health Sciences, Oslo Metropolitan University, Oslo, Norway

Acknowledgements We would like to thank the adolescents participating in the adolescent part of the Nord-Trøndelag Health Study (Young-HUNT3) and the HUNT research centre for their cooperation. The HUNT Study is a collaboration between HUNT Research Centre (Faculty of Medicine and Health Sciences, Norwegian University of Science and Technology NTNU), NordTrøndelag County Council, Centra Norway Regional Health Authority, and the Norwegian Institute of Public Health. We would also like to thank the patient representatives for their contribution to this study.

Contributors MHG processed, analysed and interpreted the data and drafted the initial manuscript. SøS, KS and J-AZ were involved in the conception and design of the manuscript, as well as data interpretation and critical review and revision of the manucript. MCS supervised the statistical analyses. MCS and MBJ were involved in critical review and revision of the manucript. All authors have read and approved the final manuscript.

Funding This work was funded by The Norwegian Fund for Post-Graduate Training in Physiotherapy, grant number 61741.

Competing interests None declared.

Patient consent for publication Not required.

Ethics approval Participationin the study was voluntary. Inclusion in Young-HUNT was based on written consentfrom participants 16 years of age or older, and from the parents of those under16 years of age, in accordance with Norwegian law. The current study has been approved by the Regional Committee for Medical Research Ethics (2014/1228/REK Sør-Øst A). The Young-HUNT Studies have been approved by REK and the Data Inspectorate of Norway.

Provenance and peer review Not commissioned; externally peer reviewed.

Data sharing statement The data set analysed belongs to a third party, the NordTrøndelag Health Study (HUNT Study). The authors of the current manuscript have been given permission to analyse the data after obtaining the necessary Norwegian permits. Research groups that wish to analyse data from the HUNT study may apply to the HUNT organisation to get access to the data (https://www.ntnu.no/hunt/ datatilgang). HUNT databank online provides a complete overview of the research variables, as well as metadata (https://hunt-db.medisin.ntnu.no/hunt-db/\#/survey/ $\mathrm{YH} 3)$. The general health questionnaire used in the study is accessible from the HUNT Bio-And-Databank (http://www.ntnu.edu/hunt/data/que).

Open access This is an open access article distributed in accordance with the Creative Commons Attribution Non Commercial (CC BY-NC 4.0) license, which permits others to distribute, remix, adapt, build upon this work non-commercially, and license their derivative works on different terms, provided the original work is properly cited, appropriate credit is given, any changes made indicated, and the use is non-commercial. See: http://creativecommons.org/licenses/by-nc/4.0/.

\section{REFERENCES}

1. Biddle SJ, Asare M. Physical activity and mental health in children and adolescents: a review of reviews. $\mathrm{Br} J$ Sports Med 2011;45:886-95.

2. Hallal PC, Victora CG, Azevedo MR, et al. Adolescent physical activity and health: a systematic review. Sports medicine 2006;36:1019-30.

3. Strong WB, Malina RM, Blimkie CJ, et al. Evidence based physical activity for school-age youth. J Pediatr 2005;146:732-7.

4. Biddle SJ, Gorely T, Stensel DJ. Health-enhancing physical activity and sedentary behaviour in children and adolescents. J Sports Sci 2004;22:679-701.

5. Sawyer SM, Afifi RA, Bearinger LH, et al. Adolescence: a foundation for future health. Lancet 2012;379:1630-40.

6. Tammelin T, Näyhä S, Hills AP, et al. Adolescent participation in sports and adult physical activity. Am J Prev Med 2003;24:22-8.

7. Kjønniksen L, Anderssen N, Wold B. Organized youth sport as a predictor of physical activity in adulthood. Scand J Med Sci Sports 2009;19:646-54.

8. Bélanger M, Sabiston CM, Barnett TA, et al. Number of years of participation in some, but not all, types of physical activity during adolescence predicts level of physical activity in adulthood: Results from a 13-year study. Int J Behav Nutr Phys Act 2015;12:76.
9. Eime RM, Young JA, Harvey JT, et al. A systematic review of the psychological and social benefits of participation in sport for children and adolescents: informing development of a conceptual model of health through sport. Int J Behav Nutr Phys Act 2013;10:98

10. Dumith SC, Gigante DP, Domingues MR, et al. Physical activity change during adolescence: a systematic review and a pooled analysis. Int J Epidemiol 2011;40:685-98.

11. Baldursdottir $B$, Valdimarsdottir $\mathrm{HB}$, Krettek $A$, et al. Age-related differences in physical activity and depressive symptoms among 10-19-year-old adolescents: A population based study. Psychol Sport Exerc 2017;28:91-9.

12. Hallal PC, Andersen LB, Bull FC, et al. Global physical activity levels: surveillance progress, pitfalls, and prospects. Lancet 2012;380:247-57.

13. McMahon EM, Corcoran P, O'Regan G, et al. Physical activity in European adolescents and associations with anxiety, depression and well-being. Eur Child Adolesc Psychiatry 2017;26:111-22.

14. Pate RR, Trost SG, Levin S, et al. Sports participation and healthrelated behaviors among US youth. Arch Pediatr Adolesc Med 2000;154:904-11.

15. Belfer ML. Child and adolescent mental disorders: the magnitude of the problem across the globe. J Child Psychol Psychiatry 2008:49:226-36.

16. Kieling $\mathrm{C}$, Baker-Henningham $\mathrm{H}$, Belfer $\mathrm{M}$, et al. Child and adolescent mental health worldwide: evidence for action. Lancet 2011;378:1515-25.

17. Bertha EA, Balázs J. Subthreshold depression in adolescence: a systematic review. Eur Child Adolesc Psychiatry 2013:22:589-603.

18. Fergusson DM, Horwood LJ, Ridder EM, et al. Subthreshold depression in adolescence and mental health outcomes in adulthood. Arch Gen Psychiatry 2005;62:66-72.

19. Christie D, Viner R. Adolescent development. BMJ 2005;330:301-4.

20. Brown BB, Larson J. Peer Relationships in Adolescence. Handbook of Adolescent Psychology 2009:74-103.

21. Rangul V, Holmen TL, Kurtze N, et al. Reliability and validity of two frequently used self-administered physical activity questionnaires in adolescents. BMC Med Res Methodol 2008;8:47.

22. Booth ML, Okely AD, Chey $T$, et al. The reliability and validity of the physical activity questions in the WHO health behaviour in schoolchildren (HBSC) survey: a population study. Br J Sports Med 2001;35:263-7.

23. Strand BH, Dalgard OS, Tambs K, et al. Measuring the mental health status of the Norwegian population: a comparison of the instruments SCL-25, SCL-10, SCL-5 and MHI-5 (SF-36). Nord J Psychiatry 2003;57:113-8.

24. Tambs K, Moum T. How well can a few questionnaire items indicate anxiety and depression? Acta Psychiatr Scand 1993;87:364-7.

25. Rosenberg M. Society and the Adolescent Self-Image. Revised edition. Middletown, CT: Wesleyan University Press, 1989.

26. Isomaa R, Väänänen JM, Fröjd $S$, et al. How low is low? Low self-esteem as an indicator of internalizing psychopathology in adolescence. Health Educ Behav 2013;40:392-9.

27. Tambs K, Røysamb E. Selection of questions to short-form versions of original psychometric instruments in MoBa. Nor Epidemiol 2014;24:195-201.

28. Cheung F, Lucas RE. Assessing the validity of single-item life satisfaction measures: results from three large samples. Qual Life Res 2014;23:2809-18.

29. Jovanović $\mathrm{V}$. The validity of the Satisfaction with Life Scale in adolescents and a comparison with single-item life satisfaction measures: a preliminary study. Qual Life Res 2016;25:3173-80.

30. Petersen AC, Crockett L, Richards M, et al. A self-report measure of pubertal status: Reliability, validity, and initial norms. J Youth Adolesc 1988;17:117-33.

31. Steinberg AM, Brymer MJ, Decker KB, et al. The University of California at Los Angeles Post-traumatic Stress Disorder Reaction Index. Curr Psychiatry Rep 2004;6:96-100.

32. Stensland SØ, Zwart JA, Wentzel-Larsen T, et al. The headache of terror: A matched cohort study of adolescents from the Utøya and the HUNT Study. Neurology 2018;90:e111-e18.

33. Hughes K, Bellis MA, Hardcastle KA, et al. The effect of multiple adverse childhood experiences on health: a systematic review and meta-analysis. Lancet Public Health 2017;2:e356-e366.

34. Stensland S $\varnothing$, Thoresen S, Wentzel-Larsen T, et al. Interpersonal violence and overweight in adolescents: the HUNT Study. Scand J Public Health 2015;43:18-26.

35. McLaughlin KA, Greif Green J, Gruber MJ, et al. Childhood adversities and first onset of psychiatric disorders in a national sample of US adolescents. Arch Gen Psychiatry 2012;69:1151-60. 
36. WHO Guidelines Approved by the Guidelines Review Committee. Global Recommendations on Physical Activity for Health. Geneva: World Health Organization, 2010.

37. Du H, King RB, Chi P. Self-esteem and subjective well-being revisited: The roles of personal, relational, and collective self-esteem. PLoS One 2017;12:e0183958.

38. Skille EÅ, Säfvenbom R. Sport policy in Norway. International Journal of Sport Policy 2011;3:289-99.

39. Marques A, Ekelund U, Sardinha LB. Associations between organized sports participation and objectively measured physical activity, sedentary time and weight status in youth. J Sci Med Sport 2016;19:154-7.

40. Dalene KE, Anderssen SA, Andersen LB, et al. Secular and longitudinal physical activity changes in population-based samples of children and adolescents. Scand J Med Sci Sports 2018;28:161-71.

41. Sagatun A, Kolle E, Anderssen SA, et al. Three-year follow-up of physical activity in Norwegian youth from two ethnic groups: associations with socio-demographic factors. BMC Public Health 2008;8:419.

42. Crane J, Temple V. A systematic review of dropout from organized sport among children and youth. Eur Phy Educ Rev 2015;21:114-31.

43. Korczak DJ, Madigan S, Colasanto M. Children's Physical Activity and Depression: A Meta-analysis. Pediatrics 2017;139:e20162266.

44. Ahn S, Fedewa AL. A meta-analysis of the relationship between children's physical activity and mental health. J Pediatr Psychol 2011;36:385-97.

45. Jerstad SJ, Boutelle KN, Ness KK, et al. Prospective reciprocal relations between physical activity and depression in female adolescents. J Consult Clin Psychol 2010;78:268-72.
46. McPhie ML, Rawana JS. The effect of physical activity on depression in adolescence and emerging adulthood: a growth-curve analysis. $J$ Adolesc 2015;40:83-92.

47. Stubbs B, Vancampfort D, Hallgren M, et al. EPA guidance on physical activity as a treatment for severe mental illness: a metareview of the evidence and Position Statement from the European Psychiatric Association (EPA), supported by the International Organization of Physical Therapists in Mental Health (IOPTMH). Eur Psychiatry 2018;54:124-44.

48. Bailey AP, Hetrick SE, Rosenbaum S, et al. Treating depression with physical activity in adolescents and young adults: a systematic review and meta-analysis of randomised controlled trials. Psychol Med 2018;48:1068-83.

49. Jewett R, Sabiston CM, Brunet J, et al. School sport participation during adolescence and mental health in early adulthood. J Adolesc Health 2014;55:640-4.

50. Brunet J, Sabiston CM, Chaiton M, et al. The association between past and current physical activity and depressive symptoms in young adults: a 10-year prospective study. Ann Epidemiol 2013;23:25-30.

51. Evans MB, Allan V, Erickson K, et al. Are all sport activities equal? A systematic review of how youth psychosocial experiences vary across differing sport activities. Br J Sports Med 2017;51:169-76.

52. Sabiston CM, Jewett R, Ashdown-Franks G, et al. Number of Years of Team and Individual Sport Participation During Adolescence and Depressive Symptoms in Early Adulthood. J Sport Exerc Psychol 2016;38:105-10.

53. Mann M, Hosman CM, Schaalma HP, et al. Self-esteem in a broadspectrum approach for mental health promotion. Health Educ Res 2004;19:357-72.

54. Ekeland E, Heian F, Hagen KB, et al. Exercise to improve selfesteem in children and young people. Cochrane Database Syst Rev 2004:CD003683. 